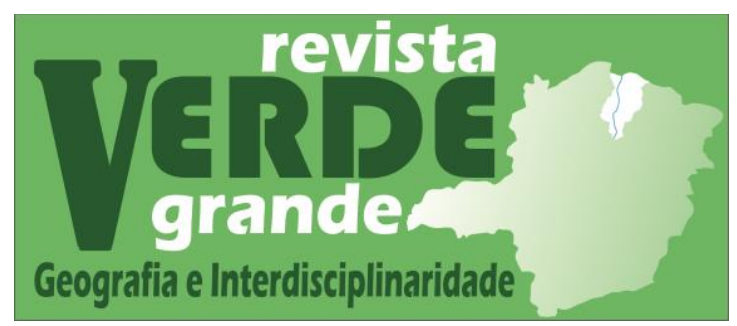

Volume 01, n‥ 02, 2019

https://www.periodicos.unimontes.br/index.php/verdegrande

\title{
LUTA E RESISTÊNCIA: O CASO DAS FAMÍLIAS CAMPONESAS DO ACAMPAMENTO JOSÉ MANOEL BANDEIRA NO MUNICÍPIO DE PIRAPORA-MG
}

\author{
Deyvison Lopes de Siqueira ${ }^{1}$ https://orcid.org/0000-0003-0393-1292
}

Gustavo Henrique Cepolini Ferreira ${ }^{2}$ https://orcid.org/0000-0003-1010-501X

\footnotetext{
${ }^{1}$ Mestrando em Geografia - Universidade Estadual de Montes Claros. E-mail: deyvisonsiqueira@ yahoo.com.br

2 Professor do Departamento de Geociências e PPGEO - Universidade Estadual de Montes Claros. E-mail: gustavo.cepolini@unimontes.br
}

\section{Resumo}

A luta das famílias camponesas na tentativa de conseguir um pedaço de terra para trabalhar é algo moroso no Brasil e pode levar até 20 anos debaixo da lona a espera da conquista pelo tão sonhado pedaço de terra. No município de Pirapora-MG, evidencia-se o caso das 160 famílias do Acampamento José Manoel Bandeira que desde 2003 estão resistindo na área da Fazenda da Prata. A metodologia baseia-se na coleta de informações por meio do trabalho de campo, conhecendo na prática a experiência direta da realidade que essas familias estão passando neste município. Os resultados do relato revelam que, mesmo diante de todas as difilcidades de acesso a serviço de saúde, escola para as crianças, moradia, acesso a aguá, energia entre outros, essas famílias camponesas permanecem na área de forma organizada, desernvolvendo atividades produtivas e de formação que são formas de manter e continuar lutando pelo sonho do pedaço de terra para morar e produzir.

Palavras-chave: Acampamento. Pirapora. Manuel Bandeira. Reforma Agrária.

Este relato é oriundo do trabalho de campo realizado na disciplina Campesinato, territótio e luta de classes, ministrada no âmbito do Programa de Pós-Graduação em Geografia da Universidade Estadual de Montes Claros. O trabalho de campo foi realizado no dia 01 de novembro de 2019 e teve como objetivo conhecer a realidade que as famílias camponesas estão enfrentando para permanecer resistindo na área da fazenda, a Fazenda da Prata, que possuiu uma área de 2.937 hectares, terras que se encontravam abandonadas. A ocupação da área acorreu em 2003 pelo Movimento dos Trabalhadores Rurais Sem Terra (MST), quando cerca de 140 famílias lutaram para ocupar e conquistar a terra (FERREIRA; MATA, 2017). Assim, ao chegar na área do acampamento, fomos recebidos por um camponês 


\section{Luta e resistência: $O$ caso das famílias camponesas do Acampamento José Manoel Bandeira município de Pirapora-MG \\ Deyvison Lopes de Siqueira; Gustavo Henrique Cepolini Ferreira}

que é um dos coordenadores do local e, logo em seguida, percorremos a maior parte da fazenda (Mapa 1).

Mapa 1: Acampamento José Bandeira em Pirapora-MG

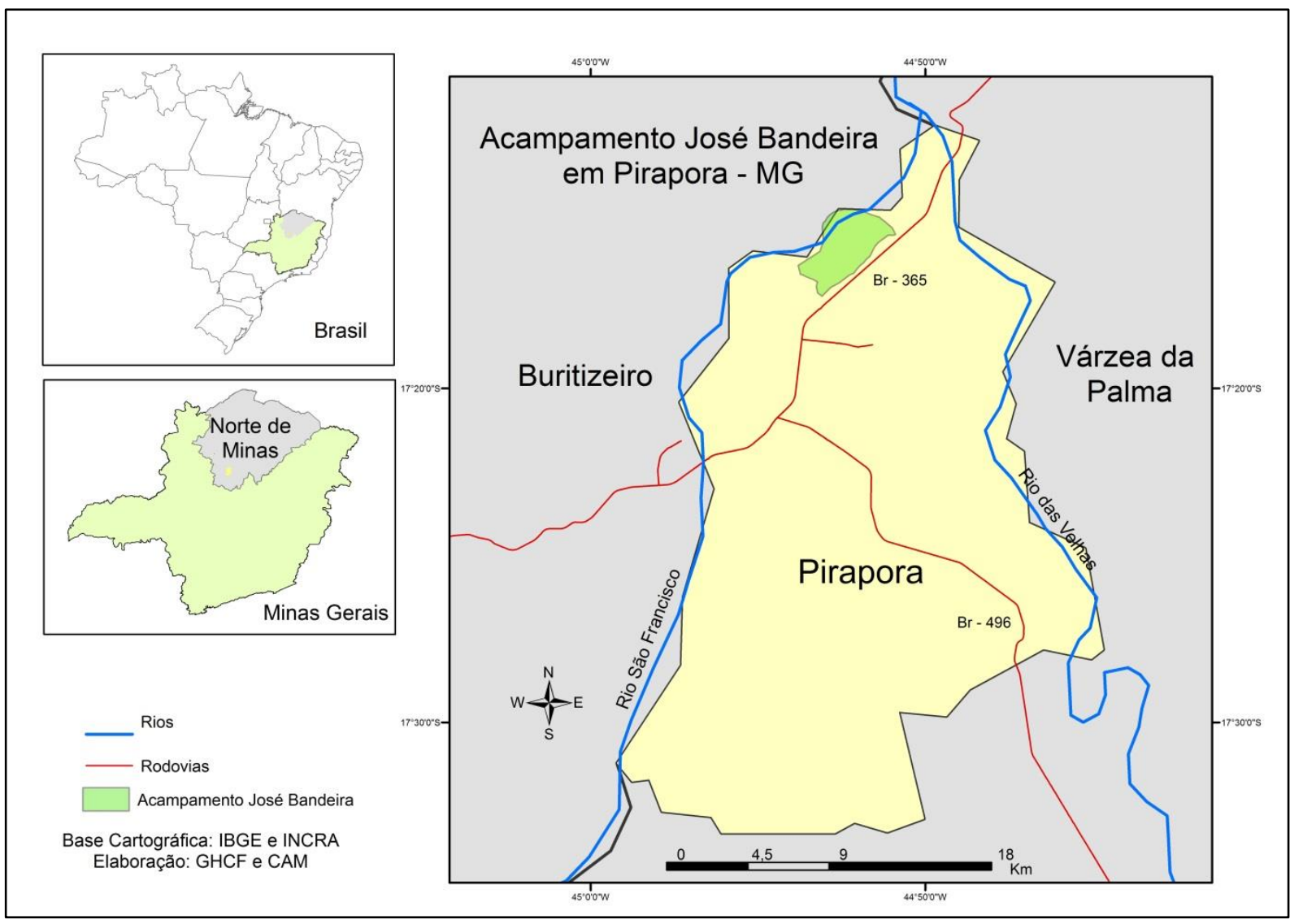

Fonte: FERREIRA; MATA, 2017, p. 61.

A partir da localização do Acampamento em Pirapora, salienta-se as imediações do rio São Francisco, fato que assegura ao futuro assentamento certa tranquilidade em relação aos recursos hídricos, tão escassos no Norte de Minas Gerais. Além disso, evidencia-se a proximidade com a rodovia, um grande diferencial para os acampados que lutam pela reforma agrária ${ }^{3}$.

Durante o percursso, foi possível notar a organização das famílias que já estão em seus barracos, alguns construídos com materiais alternativos e, outros, até de alvenaria, mostrando de fato que essas famílias querem permanecer e conquistar a área. Nesta perspectiva, o acampamento possui 160 famílias camponesas que estão acampadas desde 2003 nesta área, as quais possuem uma organização interna que permite o melhor envolvimento de todos nas atividades desenvolvidas dentro do acampamento. Essas famílias camponesas têm seus coletivos de produção por afinidade, realizam mensalmente a reunião do assentamento, participam de alguns espaços de feiras locais para escoar a produção. Desse modo, nesse

\footnotetext{
${ }^{3}$ Sobre esses desdobramentos ver a pesquisa de Mata (2019).
} 


\section{Luta e resistência: $O$ caso das famílias camponesas do Acampamento José Manoel Bandeira município de Pirapora-MG \\ Deyvison Lopes de Siqueira; Gustavo Henrique Cepolini Ferreira}

trabalho de campo, ao percorrer a área do acampamento, foi possível visualizar o trabalho e o investimento que essas famílias camponesas vêm fazendo nas áreas de produção individuais e coletivas. Ou seja, foi possível notar que esses camponeses acampados têm muita produção de hortaliças (alface, cebola, coentro, cenoura, pimenta, couve, entre outros), além do alto investimento na produção das frutíferas (maracujá, mamão, coco, pinha, goiaba), bem como a criação de pequenos animais (porco e galinha). É dessa forma que essas famílias camponesas vêm resistindo nessa conjuntura perversa e opressora, produzindo alimentos de qualidade para a alimentação da família e comercializando o excedente como estratégia de garantir uma renda complementar.

As figuras a seguir exemplificam parte do contexto sobre a produção de alimentos que as famílias do Acampamento estão produzindo.

Figuras 1 e 2: Mudas de frutíferas prontas para serem plantadas no acampamento.
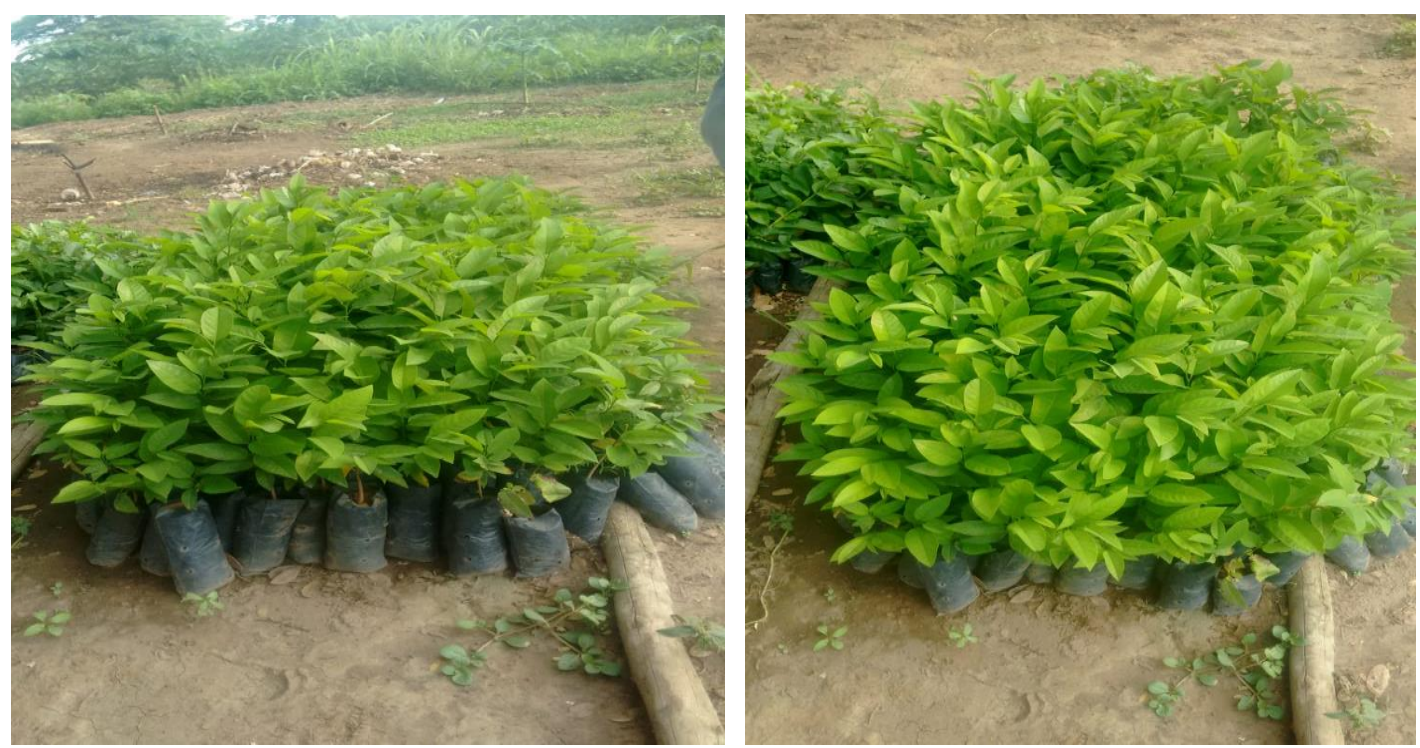

Fonte: Deyvison Siqueira, 2019. 


\section{Luta e resistência: $O$ caso das famílias camponesas do Acampamento José Manoel Bandeira município de Pirapora-MG \\ Deyvison Lopes de Siqueira; Gustavo Henrique Cepolini Ferreira}

Figuras 3 e 4: Canteiros de produção de hortaliças das famílias do acampamento.
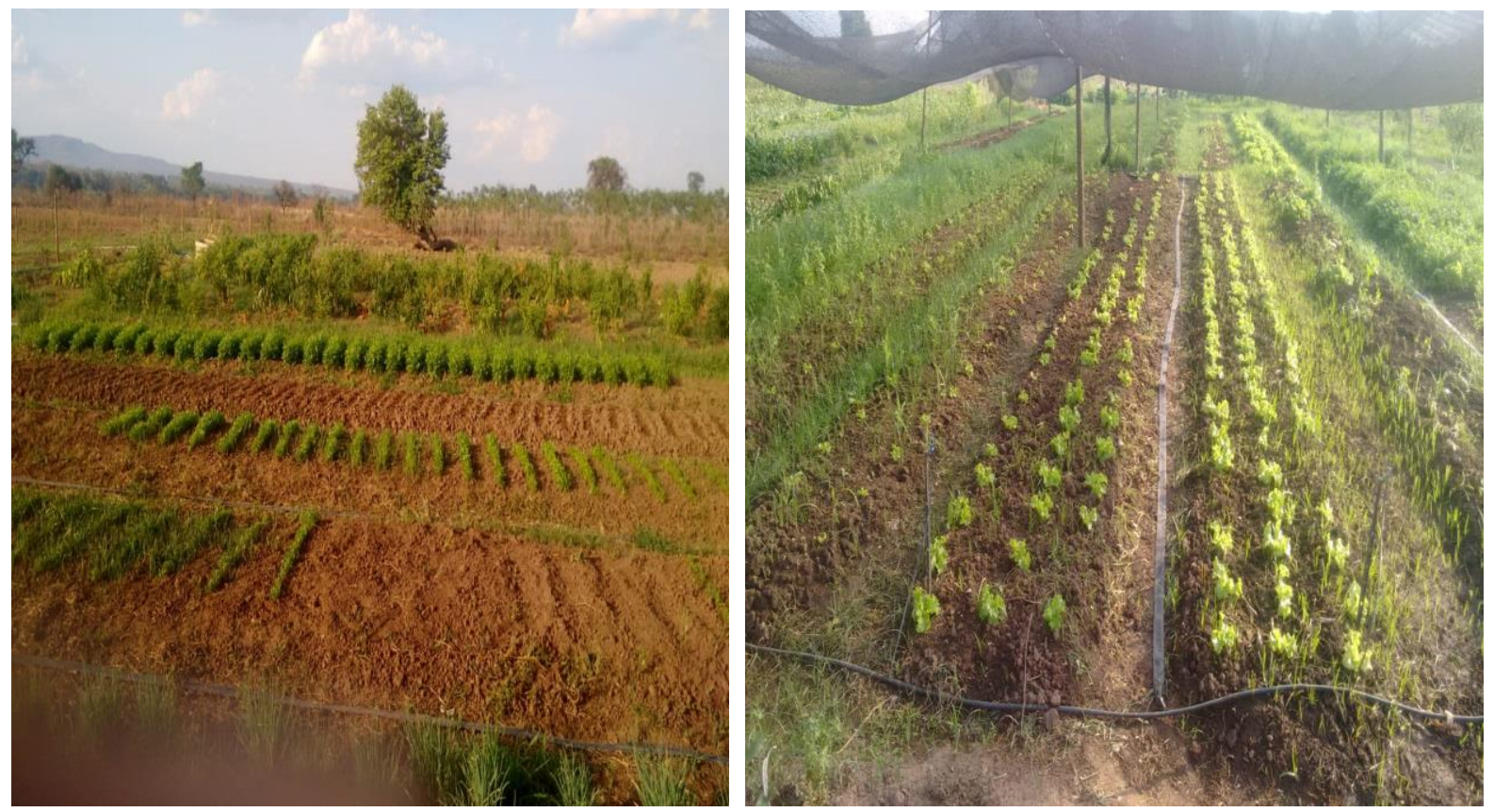

Fonte: Deyvison Siqueira, 2019.

Figuras 4 e 5: Lavoura de produção de maracujá no acampamento.

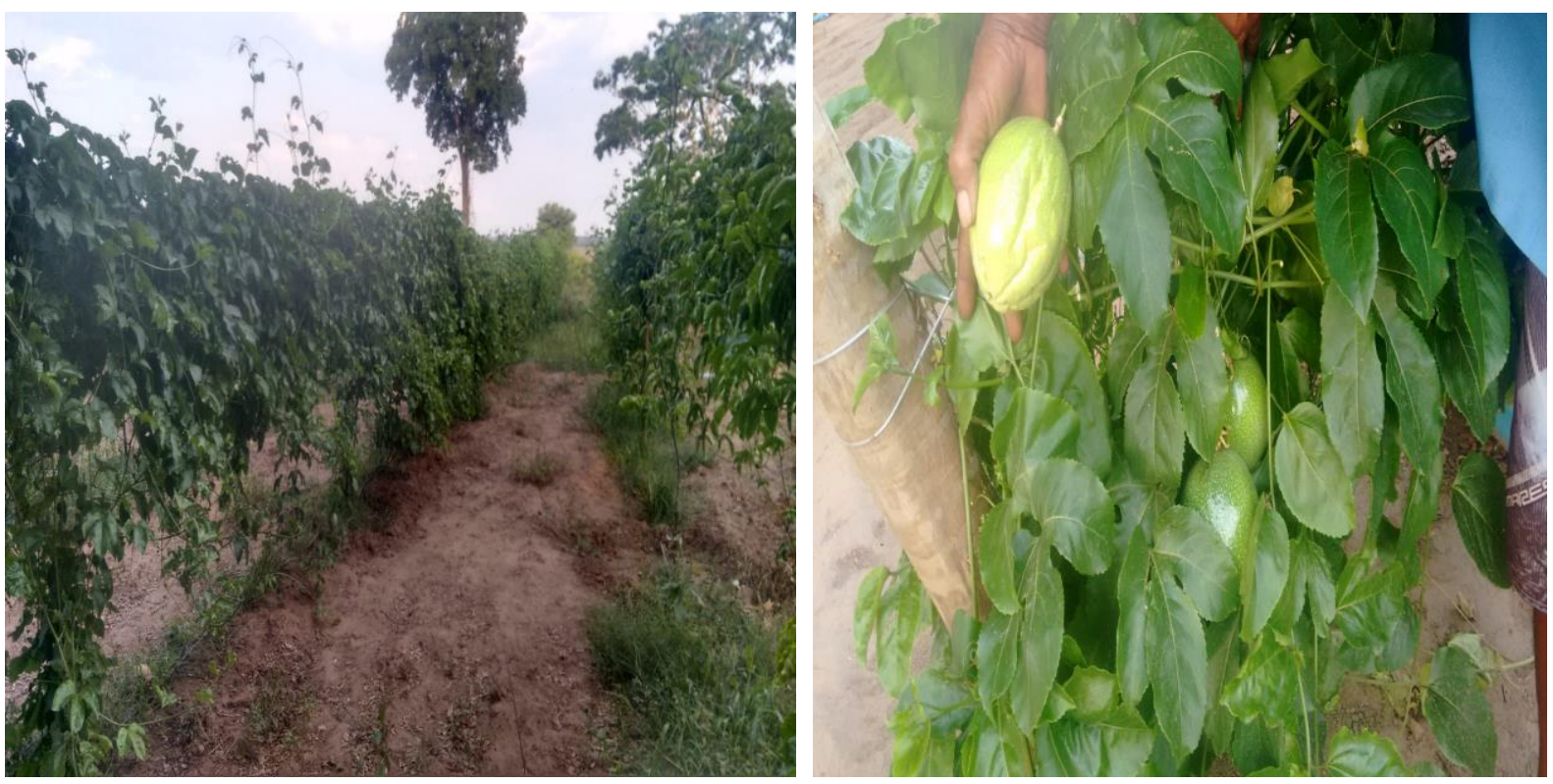

Fonte: Deyvison Siqueira, 2019.

Os acampandos seguem resistindo nessa longa marcha pela reforma agrária no Brasil, produzindo alimentos e um modo de vida que enfrenta às desgigualdades e escancara as artimanhas do latifúndio, do capital e do judiciário frente a construção de um novo modelo de desenvolvimento, que tenha como base a agricultura camponesa, o desenvolvimento rural sustentável, a diminuição da violência, do êxodo rural e da desigualdade social e territorial que 
Luta e resistência: $O$ caso das famílias camponesas do Acampamento José Manoel

Bandeira município de Pirapora-MG

Deyvison Lopes de Siqueira; Gustavo Henrique Cepolini Ferreira

nos assola cotidianamente. Assim, nota-se que os acampados do José Bandeira persistem na luta em busca da construção da autonomia na terra que virá com a reforma agrária.

\section{REFERÊNCIAS}

FERREIRA, Gustavo Henrique Cepolini; MATA, Célia de A. A trajetória dos Sem Terra no Acampamento José Manoel Bandeira em Pirapora - MG. GEOFRONTER, v. 1, p. 58-70, 2018.

MATA, Célia de Assis. O Acampamento José Bandeira e a luta pela reforma agrária: memórias da resistência camponesa em Pirapora-MG. 2019. Trabalho de Conclusão de Curso. (Graduação em Geografia). Pirapora-MG: Unimontes, 2019. 